\title{
Co-Catalyzed Tandem Pauson-Khand Type Reaction/Dimerization of Terminal Diynes in the Presence of Cyclopentadiene under CO Pressure
}

\author{
Do Han Kim, Young Keun Chung," and Jin Wook Han ${ }^{\div *}$ \\ Intelligent Textile Sustem Research Center and Department of Chemistry, College of Natural Sciences, \\ Seoul National Lniversity, Seoul 151-747, Korea "E-mail: vkchungasnuackr \\ -Department of Chemistry, Hanvang University, Seoul 133-791, Korea. "E-mail jwhanahanang.ac.kr \\ Recened January 2, 2007
}

Key Words : Tandem reaction. Pauson-Khand reaction. Cycloaddition. Diỵne. Co catalyst

Transition metal-catalyzed tandem reactions have attracted much attention due to their operational and economical efficiency in the sy'nthesis of complex organic molecules. 1.2 In particular if an intermediate is highly reactive. its further transformation in a single operation will broaden the utility of the highly reactive intemediate molecule in organic synthesis. Synthesis of novel cyclic compounds through cobalt carbonyl-catalyzed tandem cyclization including the Pauson-Khand and the related reaction has been one of our current research themes. ${ }^{3}$ Recently. we reported the utilization of the highly reactive cyclopentadienone. ${ }^{4}$ which was produced by a Pauson-Khand reaction. for the sy'nthesis of polycyclic compounds in a tandem fashion. ${ }^{3 b .3 c}$ Herein. we report cobalt-catalyzed intramolecular carbonylative cycloaddition of terminal diynes and a subsequent intermolecular cobalt-catalyzed $[2+2+2]$ cycloaddition between the cyclopentadienone intermediate and the starting terminal diyne compound in the presence of cyclopentadiene.

During the investigation of the cobalt carbonyl-catalyzed tandem cycloaddition reaction of $\alpha$ er-diynes with cyclopentadiene. it was found that two types of reaction products were obtained. One was a [4+2] cycloaddition product resulting from the carbonylative cyclization intermediate. cyclopentadienone. and cyclopentadiene. The other was a $[2+2+2]$ cycloaddition product from the cyclopentadienone intermediate and the starting $\alpha \omega$-diyne or dimerization product of the diy'ne. as shown in Figure 1.

Whereas internal diynes produced only the $[4+2]$ cycloaddition product in the Co-catalyzed tandem cycloaddition reaction with conjugated dienes. ${ }^{3}$ it was revealed in this study that terminal diynes. such as 1.6-heptadiene. resulted in a $[2+2+2]$ and $[4+2]$ cycloaddition product mixture when
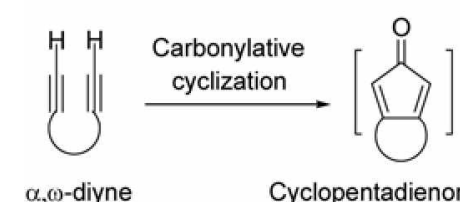

$\alpha, \omega$-diyne

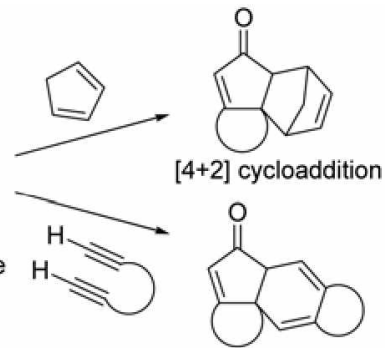

$[2+2+2]$ cycloaddition
Figure 1. Two reaction pathways of the tandem reaction of $\alpha, 0$ divnes and cyclopentadiene. the reaction occurred in the presence of cyclopentadiene Higher reactivity of terminal alkynes compared to internal alkynes may be attributed to the competition of diyne with crclopentadiene in the quenching step of the tandem catalysis. With this in mind, we carefully examined the tandem reaction for $\alpha \omega$-diynes and mono-substituted diynes and found that the steric and electronic properties of the diyne could control the reaction pathway between the $[4+2]$ and $[2+2+2]$ cycloadditions in the second step of the reaction schene (Scheme 1).

Adding diyne $1(0.8 \mathrm{mmol})$ and cỵclopentadiene (5 equiv.) to dichloromethane $(30 \mathrm{~mL})$ containing $\mathrm{Co}_{2}(\mathrm{CO})_{8}(5 \mathrm{~mol} \%)$ under $5 \mathrm{~atm}$ of $\mathrm{CO}$ pressure at $120^{\circ} \mathrm{C}$ for $18 \mathrm{~h}$ produced a mixture of $[2+2+2]$ crcloaddition product 2 from the reaction of a cyclopentadienone intennediate with diyne 1 itself and [4+2] cycloaddition product 3 from the reaction of the cyclopentadienone intenmediate with cyclopentadiene. The ratio of the products in the mixture varied according to the diyne used (Table 1).

Competition between the diyne and cyclopentadiene at the second cycloaddition step after the production of a reactive cyclopentadienone intermediate by the carbonylative cycloaddition reaction in the presence of tandem catalysis was greatly influenced by the type of tether group in the terminal 1.6-diynes. In the reaction of the diynes containing a Ctether at the 4-position. carbonylative dimerization of the diyne occurred preferentially over carbony lative $[4+2]$ cyclization of the diyne and cyclopentadiene (entries 1 and 2). Interestingly. cyclopentadiene did not take part as a diene in the cyclopentadienone quenching step in reaction of $1 \mathrm{~b}$ at all owing to the higher reactivity of dimerization of the diyne compared to cyclization with cyclopentadiene. In the reaction of the diyne (1c) containing a N-tether at the 4-position. the chemoselectivity of the reaction was reversed to give the carbonylative [4+2] cycloadduct $(3 \mathrm{c})$ as a major product (entry 3 ). In order to investigate the chemoselectivity of the

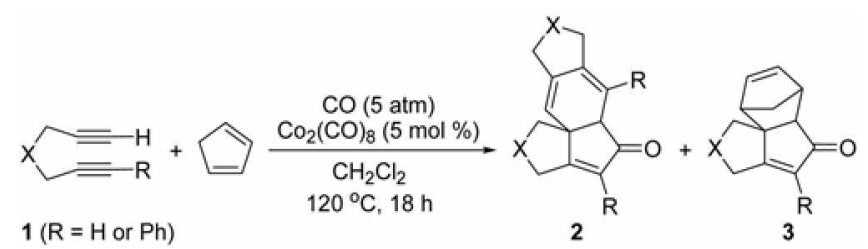

Scheme 1. Co-catalyzed tandem cycloaddition of diynes with $C p$. 
Table 1. Co-catalyzed tandem cycloaddition of teminal diynes with $\mathrm{Cp}^{2}$

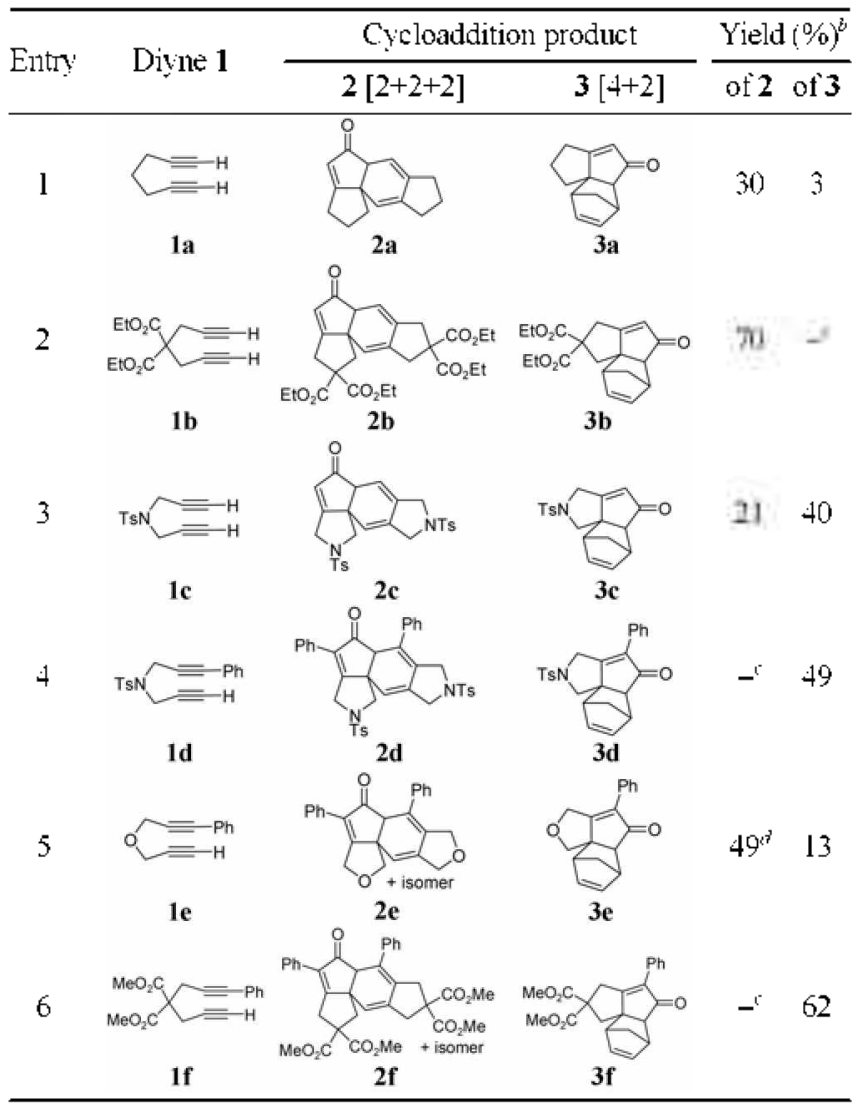

"The reaction of diyne $(0.8 \mathrm{mmol}$ ) with $\mathrm{Cp}$ (5 equif.) was cartied out under $5 \mathrm{~atm}$ of $\mathrm{CO}$ using $\mathrm{Co}_{2}\left(\mathrm{CO}_{8}\left(5 \mathrm{~mol}^{\circ} \mathrm{ib}\right)\right.$ at $120^{\circ} \mathrm{C}$ tor $18 \mathrm{~h}$ in dichloromethane $\left(30 \mathrm{~mL}\right.$ ). "Isolated vields. Not detectable in ${ }^{1} \mathrm{H}$ NMR of a crude reaction misture. "Yield of two regioisoners.

catalysis. mono-phenyl substituted diynes at one alkyne terminus were also tested as a substrate. As expected, the carbonylative [4+2] cycloadduct (3d) was the sole product in the reaction of mono-phenyl substituted diyne having a $\mathrm{N}$ tether (1d) because of the decreased reactivity of the diyne 1d (entry 4). However the reaction of mono-phenyl substituted diyne having an O-tether at the 4-position (1e) resulted in reverse chemoselectivity compared to ld (entry 5). This might be attributed to the inherent high tendency for dimerization of the parent $\mathrm{O}$-tethered diyne. In the reaction of mono-phenyl substituted diyne having a C-tether (1f). the chemoselectivity of the reaction was completely reversed compared to the substrate 1 b to give the carbonylative [4+2] cycloadduct (3f) as a sole product (entry 6). Carbonylative $[4+2]$ cyclization of the diyne and cyclopentadiene occurred preferentially over carbony lative dimerization of the diyne.

The Co-catalyzed tandem cycloaddition reaction of an internal diyne in the presence of cyclopentadiene was also examined to determine the chemoselectivity of this tandem reaction (Scheme 2). Surprisingly neither the corresponding $[2+2+1] /[2+2+2]$ nor the $[2+2+1] /[4+2]$ tandem cycloaddition products were observed under the same reaction conditions except for the intemal diyne substrate (1g). Instead. only a simple $[2+2+2]$ cycloaddition between the internal

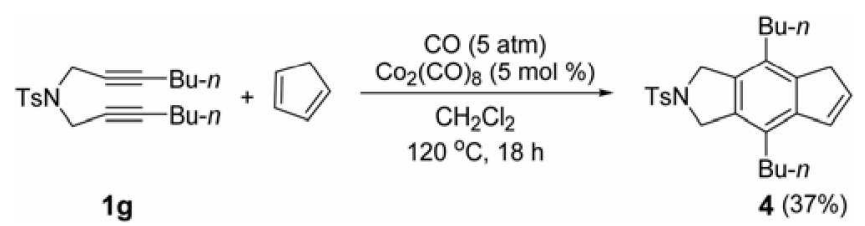

Scheme 2. Co-catalyzed cycloaddition of an internal diyne $1 \mathrm{~g}$.

diyne and cyclopentadiene occurred to give a $37 \%$ yield of the corresponding benzene derivative 4 . irrespective of the $\mathrm{CO}$ pressure. The role of $\mathrm{CO}$ in this non-carbony lative pathway could be related to catalyst regeneration and/or stability. The molecular structure of compound 4 was confinmed by $\mathrm{X}$-ray structural analy sis.

We demonstrated that the chemoselectivities of Co-catalyzed tandem $[2+2+1] /[2+2+2]$ or $[2+2+1] /[4+2]$ cycloaddition reactions of teminal diynes and cyclopentadiene under $\mathrm{CO}$ pressure are related to the type of diyne. The less reactive mono-substituted diynes prefer the carbonylative $[4+2]$ cycloaddition pathway and the more reactive teminal diynes prefer carbonylative dimerization. In addition, $\mathrm{CO}$ did not participate in the reaction using the internal diyne. The reaction of the intemal diyne was shown to have a $[2+2+2]$ cycloaddition of the diyne and cyclopentadiene. Current efforts related to the present study in our laboratory are directed towards a cobalt-catalyzed cycloaddition of intemal diynes with cyclopentadiene

Acknowledgements. This work was supported by the Korea Research Foundation grant funded by the Korean Government (MOEHRD) (KRF-2005-070-C00072) and the SRC/ERC program of MOST/KOSEF (R11-2005-065). D. H. K gives thanks for BK2l fellowships. J. W. H. is grateful for the research fund of Hanyang University (HY-2004-S).

\section{References}

1. Ajamian. A.: Gleason. J. L. Angew: Chem. Int. Ed. 2004. $\$ 3.3754$

2. (a) Sato, K.: Yudha. S.: Asao. N.: Yamamoto, Y. Symthesis 2004. 14(1)9. (b) Wang. Z. Y.: Zou. G.: Tang. J. Chem. Commin. 2004. 1192. (c) Mal, S. K.: Ray. D.: Ray. J. K. Tetrahedeon Lett. 2004, 45, 277.

3. (a) Hong, S. H; Kim. J. W. Choi. D. S.: Chung, Y. K.: Lee, S. G. Chen. Commm. 1999. 2099 (b) Son. S. U.: Chun1g. Y. K.: Lee. S. G. J. Org. Chem 2000. 65, 6142. (c) Son, S. U.: Choi, D. S: Chung. Y. K.: Lee. S. G. Org. Lett. 2000. 2. 2097. (d) Son1. S. U.: Yoon. Y. A.: Choi. D. S.: Park. T. K.: Kim. B. M.: Chunng. Y. K. Org. Lett. 2001. 3. 1065 . (e) Kim. D. H. Son, S. U.: Chung, Y. K. Chent Commm. 2002. 56. (t) Son. S. U.: Park. K. H.: Lee. S. J.: Kim. B. M.; Chung. Y. K. Sylett. 2003, 1101. (g) Kim. D. H: Chung. Y. K. Chem Conmm 2005, 1634.

4. Rainier. T. D.: Imbriglio. T. E. Org. Lett. 1999. 1. 2037

5. Representative procedure of the tandem reaction: divne $1(0.81$ mmol). cyclopentadiene ( $(0.33 \mathrm{~mL} .4 .05 \mathrm{mmol}) .30 \mathrm{~mL}$ of $\mathrm{CH}_{2} \mathrm{Cl}_{2}$. and $\mathrm{Co}_{2}(\mathrm{CO})_{3}(14 \mathrm{mg} .41 \mu \mathrm{mol})$ were added to a $100 \mathrm{mLL}$ a highpressure reactor. The reactor was heated at $120^{\circ} \mathrm{C}$ under $5 \mathrm{~atm}$ of $\mathrm{CO}$ for $18 \mathrm{~h}$. After cooling. the solution was transferred into a flask and evaporated to dryness. The residue was chromatographed on a silica gel column eluting with hexane and ethyl acetate (v:v. $10: 1)$ to give the tandem $[2+2+1][2+2+2]$ cycloadduct 2 and the tandem $[2-2-1]:[4+2]$ cycloadduet 3 .

6. See supporting information. Crystallographic data for thave been deposited with the Cambridge Crystallographic Data Centre (Deposition No. CCDC-261774). That data can be obtained free of charge via http wwwecdc cam.ac.uk perl catreq.egi. 